\title{
Bacterial derivatives of Lactococcus lactis and ectoin for atopic dermatitis: dermal compatibility and cosmetic acceptability
}

\begin{abstract}
Atopic dermatitis (AD) is a chronic skin disease characterized by disturbance of the skin barrier function. Recent studies have shown that application of non-viable bacterial derivatives can strengthen the barrier function and reduce inflammation signs. This paper describes a new emollient for AD based on bacterial derivatives (lysate of Lactococcus lactis) and ectoine, and the first results of skin compatibility and cosmetic acceptability studies.
\end{abstract}

Materials and methods: Four exploratory studies were conducted: an in vitro evaluation of irritation potential (hen's Egg Test on the chorioallantoic membrane, HET CAM); a skin irritation and sensitization potential test in healthy volunteers (HRIPT); a skin compatibility study in volunteers with atopic tendency skin (open test) and a cosmetic acceptability test in healthy pediatric volunteers.

Results: The HET-CAM test showed similar irritation potential to other products in the same category. HRIPT discarded allergenic potential and verified that no components induce sensitization reactions. Open test confirmed good skin compatibility in atopic skin. Finally, the test on children showed excellent tolerability, cosmetic acceptability and satisfaction among the parents. No participant referred skin reactions or discomfort feelings.

Discussion: Both the in vitro and in vivo studies confirmed the good tolerability, skin compatibility and cosmetic acceptability of this new emollient containing lysate of Lactococcus lactis and ectoin. The emollient represents a new approach for restitution of the cutaneous barrier in patients with $\mathrm{AD}$, through the topical application of the lysate of probiotic bacteria, which acts on the epidermis thereby strengthening the skin barrier, and combined with ectoin, which protects the cell membrane and prevents transepidermal water loss (TEWL).

Keywords: atopic dermatitis, probiotics, Lactococcus lactis, bacterial derivatives, emollient
Volume 5 Issue 6 - 2017

\author{
Cynthia Crespo \\ Primary Care Paediatrician, CAP Montclar, Spain
}

Correspondence: Cynthia Crespo, Primary Care Paediatrician, CAP Montclar, Pi i Margall, II 508830 Sant Boi de Llobregat (Barcelona), Spain, Tel +34 609141284, Email crafree2017@gmail.com

Received: September 04, 2017 | Published: December 27, 2017
Abbreviations: AD, atopic dermatitis; HET CAM, hen's egg test on the chorioallantoic membrane; HRIPT, human repeat insult patch testing; TEWL, transepidermal water loss; AMPs, antimicrobial peptides; UV-B radiation, ultraviolet-b radiation; Th 2, t-helper 2 lymphocyte;

\section{Introduction}

Atopic dermatitis (AD) is a chronic inflammatory skin disease with a genetic basis, affecting between $15 \%-30 \%$ of children and $2 \%-10 \%$ of adults. ${ }^{1}$ This skin condition can result in an uncontrolled inflammatory cascade causing scaling, itching and redness. Typically, the skin presents dryness or xerosis due to cutaneous barrier dysfunction and usually is accompanied by pruritus and scratching, favouring the penetration of allergens and infections. ${ }^{2-4}$ The skin barrier function not only acts as a physical protection against the external environment, but also as a biochemical and immunological barrier. ${ }^{5}$ Keratinocytes are protein-enriched cells, linked together by desmosomes, which undergo a differentiation process as they migrate from the basal layer to the stratum corneum, transforming into corneocytes without nucleus immersed in lipid-enriched intercellular space. ${ }^{6}$ Keratinocytes express a large number of specific proteins, including filaggrin and antimicrobial peptides (AMPs). ${ }^{2}$ This corneal layer provides mechanical strength and epidermal ability to neutralize some reactive oxygen species, absorb UV-B radiation, prevent the infiltration of allergens and microorganisms and limit water and electrolyte loss. ${ }^{7}$ Many atopic skins have genetic defects that affect filaggrin and caspase, which are both involved in stratum corneum formation and the integrity of the cutaneous barrier. Filaggrin is an epidermal protein that is crucial to the formation of the corneocyte and the generation of intracellular metabolites its reduction or absence due to genetic mutations can lead to the development of $\mathrm{AD}$ and other skin disorders such as ichthyosis. ${ }^{8,9}$ Caspase is a proteolytic enzyme essential to the maturation of the epidermis and formation of the stratum corneum. Its absence, dysfunction or reduced expression due presence of citokines causes alterations in the skin barrier function with the increase of TEWL. ${ }^{10-12}$ In addition, AD affected skins present decreased secretion of antimicrobial peptides (AMPs), small cationic peptides with a broad antimicrobial activity that play an important role in both the innate and adaptive immune responses and show direct chemotactic and immunomodulating properties, ${ }^{13}$ and binding with anionic components in the cell membrane of microbes can cause rupture and consequent death. ${ }^{14}$ The decreased levels of AMPs in AD 
are attributable to elevated Th2 cytokines $^{15}$ and are associated with increased susceptibility to skin infections.

The usual treatment of $\mathrm{AD}$ is based on anti-inflammatory drugs (topical corticosteroids) or immunomodulators (topical inhibitors of calcineurin) to decrease inflammation, and the use of moisturizers and emollients for hydration and recovery from barrier function reducing TEWL. ${ }^{16-19}$ However, as the pathophysiological mechanisms and underlying processes of the disease advance, new targets emerge for the treatment of AD. ${ }^{5}$ Recent studies suggest that the use of probiotics provides benefits in terms of skin health and can help to prevent AD. ${ }^{20-22}$ Similarly, non-viable bacterial derivatives have been shown to exert antimicrobial and immunomodulating action and can elicit certain immune responses on the skin and improve skin barrier functions. ${ }^{23}$ It has been found that the application of lysates of probiotic bacteria, such as the Lactobacillus or Bifidobacterium species, on in vitro models increase the barrier function through the modulation of tight-junction protein components and decrease skin reactivity, the release of cytokines and signs of inflammation. ${ }^{24,25}$ In addition, trials in healthy volunteers have shown that topical application of bacterial lysates in the form of a cream strengthens the barrier function and decreases skin dryness. ${ }^{25}$ ProRenew Complex $\mathrm{CLR}^{\mathrm{TM}}$ is a new ingredient obtained from a gram-positive probiotic bacterium, Lactococcus Lactis. It acts by accelerating the self-renewal ability of the skin, helping it to adapt quickly and effectively to external stress. It increases the production of essential proteins and enzymes in order to maintain the quality of the stratum corneum and increases the synthesis of AMPs. A new product specifically designed for use on atopic skin now exists. It is an emollient that combines lysate of Lactococcus Lactis (ProRenew Complex CLR ${ }^{\mathrm{TM}}$ ), which acts by promoting skin regeneration and barrier function recovery, and ectoin, a substance that prevents dehydration and reinforces the barrier function. ${ }^{26,27}$ In addition, the product also contains other components with emollient properties already widely used in the manufacture of cosmetics and creams, including squalene, panthenol and shea butter. ${ }^{28-30}$ This paper describes the first exploratory studies on this new emollient in order to assess its skin compatibility and cosmetic acceptability.

\section{Materials and methods}

Four pilot studies were conducted to assess the tolerability and acceptability of the new specific emollient cream with lysate of Lactococcus lactis and ectoin. All the studies were single-center, and they were performed at contracted European facilities, officially authorized and specialized in this type of testing, in accordance with the principles of Good Laboratory Practices, Good Clinical Practice and the Declaration of Helsinki. Full and informed consent was obtained from all participating subjects prior to their involvement in the various test procedures.

\section{Irritant potential test (Hen's egg test on the chorioallantoic membrane, HET CAM)}

This in vitro blinded controlled study uses an adaptation of the technique described by Luepke \& Kemper. ${ }^{31}$ It is based on the observation, by a trained specialist, of the irritant effects (hyperemia, hemorrhage and coagulation) occurring during the five minutes after application of the test product to the chorioallantoic membrane of embryonated hen's eggs at the tenth day of incubation (HET CAM). The test was performed on 4 eggs with $300 \mu 1$ deposited on the CAM. After 2seconds contact, the CAM was rinsed with sodium chloride isotonic solution. Possible irritation phenomena were observed over a period of 5 minutes. The irritant potential was scored according to a scale from 0 to 21 . The tested product was classified according to the mean score obtained:

a) Practically non-irritant (mean score $<1$ );

b) Slightly irritant (mean score $<5$ );

c) Moderately irritant (mean score $<9$ );

d) Irritant (mean score $\geq 9$ ). The blind control was performed through a standard curve of $0.05 \%, 0.4 \%$ and $3.2 \%$ lauryl sulfobetaine solutions in water.

\section{Skin compatibility and allergenic potential test - Human Repeated Insult Patch Test (HRIPT)}

This, single-center, controlled exploratory study uses an adaptation of that described by Marzulli \& Maibach. ${ }^{32}$ The study was conducted on 51 healthy volunteers with cutaneous phenotype (Fitzpatrick) II to IV and reactive skin. Subjects with cutaneous marks on the experimental area, skin lesions, atopy or allergies were excluded. Approximately $20 \mu \mathrm{l}$ or $20 \mathrm{mg}$ of product was applied under an occlusive patch on 9 consecutive occasions and removed after $48 \mathrm{~h}-72 \mathrm{~h}$ of contact over a period of 3 consecutive weeks. Then, after a minimal 2 week rest period with no treatment, a single application of each product was repeated to the induction site, under a patch, and to a virgin site to reveal any possible induced allergy. One control patch, corresponding to the identical type of material and containing an ad hoc quantity of distilled water, was applied at the same time. The presence and intensity of cutaneous signs (erythema, edema, vesicles, bullas, papules, scabs, dryness, coloration and soap effects) were evaluated. Subjects were also asked to fill out a questionnaire on the main sensations of discomfort (i.e. heat sensations, stinging, pruritus etc.). The results were expressed as follows: percentage of reactive subjects (taking visible signs of irritation into account only: erythema, edema, vesicles, bullas, papules and scabs); and descriptively for any other signs or feelings of discomfort. Skin compatibility and absence of allergenic potential were assessed in all subjects included. Allergenic potential was assessed according to a scale established by the ICDRG (International Contact Dermatitis Research Group).

\section{Skin compatibility test (Open test)}

This open study was conducted on ten volunteers with cutaneous phenotype (Fitzpatrick) II to IV and atopic skin. The experimental procedure consisted of applying $0.3 \mathrm{~g}$ of product in the chosen areas (half face and a forearm) once daily for 5 consecutive days. The other half face and forearm served as controls. Compatibility was monitored by a dermatologist at each visit with visual examination of the skin prior to application and during the hour following the application. After each application, subjects were also asked about any sensations of discomfort.

\section{Cosmetic acceptability test in children (use test)}

This pilot non-controlled study was designed to check the acceptability and the cosmetic qualities and efficacy, after application under normal conditions. Fifty-three children with atopic skin or very dry skin have participated. Subjects with other skin pathology or cutaneous affection, and subjects with general or local antiinflammatory or anti-allergic medication were excluded. Acceptability was checked daily by the parents after each application and the 
experimental area was controlled by pediatrician. The cosmetic qualities and efficacy were assessed at the end of study using a target questionnaire. The progenitors were asked to record any reaction or sensation of discomfort. We present the results of each study using descriptive statistics. Data are shown including number of subjects, means and standard deviation (means $\pm \mathrm{SD}$ ) for numerical variables and with absolute and relative frequencies (percentages) in the case of categorical variables.

\section{Results}

\section{In vitro HET CAM test}

Following application of the product, none of the eggs presented signs of hyperemia or coagulation, but did show evidence of haemorrhage ( 3 in less than 30seconds and 1 in less than 2minutes). The mean $\pm \mathrm{SD}$ score was $6.5 \pm 1.0$, so that the cream studied was classified as moderately irritant.

\section{Clinical skin reaction testing (HRIPT)}

The $90.2 \%(46 / 51)$ of the participating subjects were women. The average age was $54.3 \pm 10.7$ (ranging from 23 to 68years of age) divided between the following skin phenotypes (Fitzpatrick): $\mathrm{II}(25.5 \%), \operatorname{III}(62.7 \%)$ and IV(11.8\%). None of the subjects $(0 / 51$;
$0 \%)$ presented any type of skin reaction. No irritation reaction was observed during the induction phase (from D3 to D24), nor allergic reactions during the single patch application phase.

\section{Skin compatibility test (open test)}

None of the subjects showed clinical signs attributable to the product or noticed sensations of discomfort. Accordingly, the dermatologist classified the product as very well tolerated by the skin (good cutaneous compatibility) in subjects with atopic tendencies.

\section{Test of use on pediatric subjects}

None of the children noticed irritating sensations or showed clinical signs attributable to the product. The pediatrician classified the cream as very well tolerated in accordance with the established classification scale. Children's parents rated the cosmetic qualities of the cream very highly (see Figure 1) and declared themselves to be either satisfied or very satisfied with the cosmetic efficacy of the product in terms of moisturizing the skin $(100 \%)$, nourishing the skin (100\%), leaving the skin soft and smooth (100\%), leaving the skin more flexible and elastic (98\%), providing a sensation of comfort (96\%) and improving the general state of the skin $(100 \%)$. At the end of the test $94 \%$ of the parents confirmed that they were happy with the results. Table 1 shows a summary of the main results.

Table I Summary of skin compatibility and cosmetic acceptability tests performed

\begin{tabular}{|c|c|c|c|c|c|}
\hline Study type & $\begin{array}{l}\text { Number } \\
\text { of } \\
\text { subjects }\end{array}$ & Product & Variables & $\begin{array}{l}\text { ResultsN (\%)/ } \\
\text { mean } \pm \text { SD }\end{array}$ & Summary of results \\
\hline \multirow{4}{*}{$\begin{array}{l}\text { Irritant potential } \\
\text { test HET CAM }\end{array}$} & \multirow{4}{*}{4 eggs } & & Hyperemia & $0.0 \pm 0.0$ & \multirow{4}{*}{$\begin{array}{l}\text { According to the defined } \\
\text { scale product tested } \\
\text { was considered as } \\
\text { moderately irritant }\end{array}$} \\
\hline & & 300 ul deposited & Haemorrhage & $6.5 \pm 1.0$ & \\
\hline & & \multirow[t]{2}{*}{ on the CAM } & Coagulation & $0.0 \pm 0.0$ & \\
\hline & & & Global score & $6.5 \pm 1.0$ & \\
\hline \multirow{9}{*}{$\begin{array}{l}\text { Skin } \\
\text { compatibility } \\
\text { HRIPT }\end{array}$} & \multirow{9}{*}{$\begin{array}{l}51 \text { healthy } \\
\text { volunteers }\end{array}$} & \multirow{9}{*}{$\begin{array}{l}20 \mathrm{mg}(9 \\
\text { applications } \\
\text { under patch over } \\
3 \text { consecutive } \\
\text { weeks+ single } \\
\text { application after } \\
2 \text { to } 4 \text { weeks rest } \\
\text { period) }\end{array}$} & Sex: men/women & 5 (9.8\%)/46 (90.2\%) & \multirow{9}{*}{$\begin{array}{l}\text { The product induced } \\
\text { no reaction of irritation } \\
\text { thus product has a "very } \\
\text { good skin compatibility". } \\
\text { Moreover, no allergic } \\
\text { reaction was detected } \\
\text { and the product may be } \\
\text { considered "hypoallergenic" }\end{array}$} \\
\hline & & & Age (years old) & $54.3 \pm 10.7$ & \\
\hline & & & \multirow[t]{2}{*}{ Phenotype (Fitzpatrick) } & II: $25.5 \%$ & \\
\hline & & & & III: $62.7 \%$ & \\
\hline & & & II/III/IV & IV: II.8\% & \\
\hline & & & \multirow[t]{2}{*}{$\begin{array}{l}\text { Induction phase - from D3 to } \\
\text { D22- (\%) reactive subjects on } \\
\text { the induction site }\end{array}$} & $\begin{array}{l}\text { Sings of reactivity: } 0 \\
(0.0 \%)\end{array}$ & \\
\hline & & & & $\begin{array}{l}\text { Sensations of } \\
\text { discomfort: } 0(0.0 \%)\end{array}$ & \\
\hline & & & $\begin{array}{l}\text { Challenge phase - from D36 } \\
\text { to D40 - (\%) reactive subjects }\end{array}$ & $\begin{array}{l}\text { Sings of reactivity: } 0 \\
(0.0 \%)\end{array}$ & \\
\hline & & & $\begin{array}{l}\text { on the induction site and } \\
\text { virgin site }\end{array}$ & $\begin{array}{l}\text { Sensations of } \\
\text { discomfort: } 0(0.0 \%)\end{array}$ & \\
\hline Open test & $\begin{array}{l}10 \\
\text { volunteers } \\
\text { with } \\
\text { atopic } \\
\text { skin }\end{array}$ & $\begin{array}{l}0.3 \mathrm{~g} \text { applied over } \\
\text { each site (once } \\
\text { daily during } 5 \\
\text { consecutive days) }\end{array}$ & Sensations of discomfort & $\begin{array}{l}\text { Sings of reactivity: } 0 \\
(0.0 \%)\end{array}$ & $\begin{array}{l}\text { The product induced no } \\
\text { reaction of irritation thus } \\
\text { product has a "very good } \\
\text { skin compatibility" }\end{array}$ \\
\hline
\end{tabular}


Table Continued..

\begin{tabular}{|c|c|c|c|c|c|}
\hline Study type & $\begin{array}{l}\text { Number } \\
\text { of } \\
\text { subjects }\end{array}$ & Product & Variables & $\begin{array}{l}\text { ResultsN (\%)/ } \\
\text { mean } \pm \text { SD }\end{array}$ & Summary of results \\
\hline $\begin{array}{l}\text { Cosmetic } \\
\text { acceptability Use } \\
\text { test in children }\end{array}$ & $\begin{array}{l}53 \\
\text { children }\end{array}$ & $\begin{array}{l}\text { Application of the } \\
\text { product at home } \\
\text { (under the normal } \\
\text { conditions of use) }\end{array}$ & $\begin{array}{l}\text { Skin reactions ascribable to } \\
\text { the test product Sensations of } \\
\text { discomfort ascribable to the } \\
\text { test product }\end{array}$ & $\begin{array}{l}\text { I like it: } 94 \% \\
\text { Neither like it nor } \\
\text { dislike it: } 4 \% \\
\text { Don't like it: } 2 \%\end{array}$ & $\begin{array}{l}\text { The product has"very good } \\
\text { skin compatibility". It's very } \\
\text { good skin tolerance was } \\
\text { thus confirmed.A statistical } \\
\text { significant percentage } \\
\text { of parents judged that } \\
\text { product moisturizes and } \\
\text { nourishes skin, leaves skin } \\
\text { softer, smoother, suppler } \\
\text { and elastic, provides a } \\
\text { general comfort sensation } \\
\text { and improves the general } \\
\text { condition of skin }\end{array}$ \\
\hline
\end{tabular}

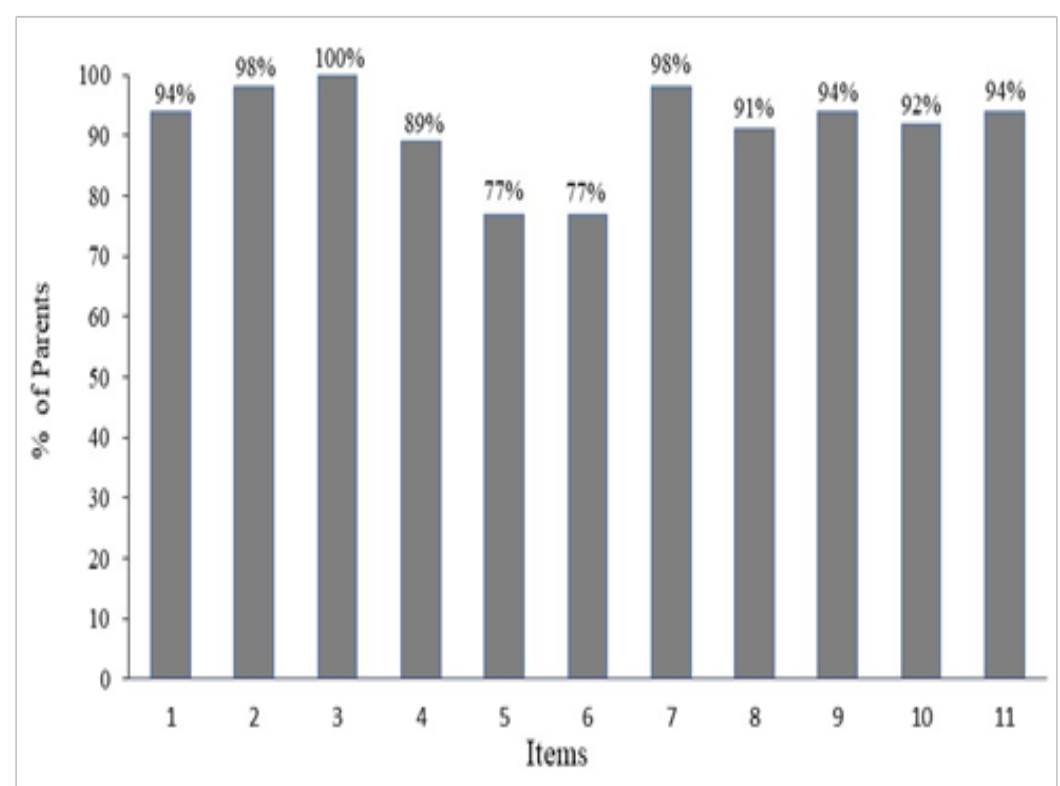

Figure ICosmetic qualities: the percentage of satisfied parents for each item.

Items: I. The general application of the product on skin is easy; 2. Product consistency is just right; 3 . Product color is pleasant; 4 . Product absorption is quick; 5. Product fragrance is pleasant; 6. The intensity of the fragrance is just right; 7. It has pleasant texture; 8. It spreads easily on skin; 9. Does not leave an oily sensation on skin; I0. Does not leave a sticky sensation on skin; I I. Does not leave residues after application.

\section{Discussion}

The results obtained in these studies indicated the good cutaneous compatibility and cosmetic acceptability in children of the new emollient product containing lysate of Lactococcus Lactis and ectoin, designed, as an adjuvant to pharmacological treatment for atopic dermatitis. The use of moisturizing creams and emollients is already considered an integral part of therapy in the treatment of AD. ${ }^{33,34}$ However, the use of probiotics and bacterial derivatives to re-establish the skin barrier and improve the condition represents a new therapeutic development. In the HET CAM in vitro test for potential irritants (now considered a viable alternative to in vivo testing on rabbits), ${ }^{35}$ the product being classified as moderately irritant. These results were close to other products of the same cosmetic category (body moisturizing lotions for babies and facial moisturizers for adults), thus, equally well tolerated as these existing products. The HRIPT on healthy volunteers showed scarce irritant potential in the product and an absence of allergic skin reactions following repeated application. In general, adverse reactions to cosmetic products occur due to one of their primary components, by contamination during formulation or as a result of one of the added preservatives or fragrances. In most cases the reactions are irritant rather than allergic and only minor or transitory such as itching, stinging or a rash on contact. In very few cases are the reactions more serious. ${ }^{20}$ With the tested product, neither 
the Lactococcus bacterial lysates nor the other components have induced skin sensitivity reactions in any of the healthy volunteers. In terms of cutaneous compatibility in subjects with atopic tendencies, the absence of clinical signs or unpleasant sensations on the part of the volunteers showed the cream to be well suited for use on atopic skin, leading to the dermatologist classifying it as a product with very good cutaneous compatibility.

Finally, the cosmetic acceptance test on child subjects under the control of a pediatrician showed very good cutaneous tolerance, with none of the children complaining of unpleasant sensations in relation to the use of the cream. The parents positively rated the cosmetic qualities of the cream and declared themselves satisfied with the cosmetic effectiveness of the product. The product studied is an emollient with a new composition which contains lysate of Lactococcus Lactis. The use of topical probiotics and their derivatives in the treatment of AD is a growing trend. Although the link between Staphylococcus aureus and $\mathrm{AD}$ lesions has been known for some time, most of the research over recent years has focused on the study of cutaneous microbiota and the changes in its composition in relation to dermatological illnesses such as $\mathrm{AD}$, where there is a reduction in the microbial diversity due to the rapid growth of S. aureus and an increase of other species in lesional skin, ${ }^{4-36}$ related to the deterioration of the barrier function. The oral intake of probiotics provides health benefits for the skin, including an improvement in cases of eczema and $\mathrm{AD}$, curing burns and scars, betterment rejuvenation properties and an improvement to the innate immunity of the skin. ${ }^{23}$ Likewise, administering during pregnancy and early infancy can reduce the risk of eczema developing. ${ }^{20}$ More recently, topical application of probiotics and bacterial composites such as the cellular wall, its metabolites and dead bacteria has also been shown to produce certain immunity responses in the skin and to improve and reinforce the skin barrier. ${ }^{23-25}$ In cases of $\mathrm{AD}$ selective defects exist in the expression of the multiple genes which codify the corneal layer of the skin, including the filaggrin or the loricrin which only show $2 \%$ of the normal level, with structural alterations and a reduction in the corneocytes and the intercellular lipids. As a result, the whole process of terminal differentiation of the keratinocytes (cytoplasmic compaction, cornification and the release of lipids) necessary for the establishment of the barrier function is defective. ${ }^{37}$ Furthermore, the reduction in the antimicrobial activity makes the patient susceptible to skin infections, sensitivity to allergens and a state of constant inflammation. ${ }^{38}$

Lysate of Lactococcus Lactis acts to promote the maturation and regeneration of the skin. It increases the expression of structural proteins such as loricrin, transglutaminase 1, profilaggrin, filaggrin and caspase 14, thickens the epidermis and improves the integrity of the barrier by increasing cellular cohesion and the production of antimicrobial peptides. The other main component of the product studied, ectoin, is a natural compound produced by various bacterial species in response to osmotic pressure in extreme environmental conditions. It is a compatible solute which attaches itself to the water molecules and acts as an osmoprotectant. ${ }^{39}$ Various studies have indicated that topical application of ectoin on human skin has beneficial effects. It has been shown that it protects the cellular membrane from the damage caused by surfactants (present in many cosmetic products) and reinforces the barrier function against water loss, improving skin resistance and preventing dehydration. ${ }^{27}$ Like Marini et al. ${ }^{26}$ demonstrated that the application of a cream containing ectoin twice a day over a 28 day period to the damaged skin of patients with light to moderate $\mathrm{AD}$ reduced the seriousness of the condition and was very well tolerated. The other components of the product include panthenol, squalene and shea butter. Panthenol or vitamin B5 is a component of coenzyme A which serves as a cofactor for a wide variety of metabolic reactions and is essential for normal epithelial function. Administered topically, it acts to improve the hydration of the corneal layer, reducing TEWL and maintaining the softness and elasticity of the skin without harming the bacterial microbiota. ${ }^{40}$ Squalene is a natural lipid which is found in humans, animals and vegetable species. It forms part of the sebaceous secretion of the skin and provides beneficial properties such as antioxidant, anti-tumour and cytoprotective effects. ${ }^{41}$ It is a substance widely used as an excipient in pharmaceutical formulations for the treatment of conditions such as seborrheic dermatitis, acne, psoriasis and atopic dermatitis and in cosmetic products with therapeutic or pharmacological effects for skin care due to their high emollient properties and ease of absorption without leaving greasy residue. ${ }^{42}$ Shea butter is a vegetable lipid used in cosmetics and creams for its emollient and conditioning properties for use on dry skin. ${ }^{43}$

\section{Conclusion}

The results obtained show the good tolerability and cutaneous compatibility of the cream under study. There were no irritant signs or allergic reaction following repeated application on the study subjects, demonstrating the absence of allergenic potential. Likewise, the use test on a pediatric population showed it to be a cream well suited for use on children and it was well received by the parents who expressed their satisfaction with the cosmetic effectiveness and qualities of the product. These were the first studies conducted on this emollient, which represents a new approach for restoring the integrity of the cutaneous barrier aimed at patients with $\mathrm{AD}$, involving the topical application of a lysate of Lactococcus Lactis which acts to promote the maturation and regeneration of the skin, thickening the epidermis and improving the integrity of the barrier by increasing cellular cohesion and the production of antimicrobial peptides. In addition, the combinations of the latter with ectoin, a substance which protects the cellular membrane and prevents transepidermal water loss, make the product's use especially suitable for acute outbreaks. Following testing on the tolerability and acceptability of this new emollient, the next step will be to conduct further clinical studies to assess the clinical effectiveness and safety of the cream in common medical practice.

\section{Acknowledgements}

None.

\section{Conflict of interest}

The author reports no conflicts of interest. Funding to perform in vitro and in vivo studies was provided by JULUTIONS, S.L. (Barcelona, Spain).

\section{References}

1. Bieber T. Atopic dermatitis. Ann Dermatol. 2010;22(2):125-137.

2. Proksch E, Folster-Holst R, Jensen JM. Skin barrier function, epidermal proliferation and differentiation in eczema. J Dermatol Sci. 2006;43(3):159-169.

3. Hauser C, Wuethrich B, Matter L, et al. Staphylococcus aureus skin colonization in atopic dermatitis patients. Dermatologica. 1985;170(1):35-39. 
4. Kong HH, Oh J, Deming C, et al. Temporal shifts in the skin microbiome associated with disease flares and treatment in children with atopic dermatitis. Genome Res. 2012;22(5):850-859.

5. Le Lamer M, Pellerin L, Reynier M, et al. Defects of corneocyte structural proteins and epidermal barrier in atopic dermatitis. Biol Chem. 2015;396(11):1163-1179.

6. Proksch E, Brandner JM, Jensen JM. The skin: an indispensable barrier Exp Dermatol. 2008;17(12):1063-1072.

7. Elias PM. Skin barrier function. Curr Allergy Asthma Rep 2008;8(4):299-305.

8. Thyssen JP, Kezic S. Causes of epidermal filaggrin reduction and their role in the pathogenesis of atopic dermatitis. J Allergy Clin Immunol. 2014;134(4):792-799.

9. O'Regan GM, Sandilands A, McLean WH, et al. Filaggrin in atopic dermatitis. J Allergy Clin Immunol. 2009;122(4):689-693.

10. Jung M, Choi J, Lee SA, et al. Pyrrolidone carboxylic acid levels or caspase-14 expression in the corneocytes of lesional skin correlates with clinical severity, skin barrier function and lesional inflammation in atopic dermatitis. J Dermatol Sci. 2014;76(3):231-239.

11. Thyssen JP, Laursen AS, Husemoen LL, et al. Variants in caspase-14 gene as risk factors for xerosis and atopic dermatitis. J Eur Acad Dermatol Venereol. 2016;30(3):446-448.

12. Hvid M, Johansen C, Deleuran B, et al. Regulation of caspase 14 expression in keratinocytes by inflammatory cytokines--a possible link between reduced skin barrier function and inflammation? Exp Dermatol. 2011;20(8):633-636.

13. Clausen ML, Slotved HC, Krogfelt KA, et al. In vivo expression of antimicrobial peptides in atopic dermatitis. Exp Dermatol. 2016;25(1):3-9.

14. Izadpanah A, Gallo RL. Antimicrobial peptides. J Am Acad Dermatol. 2005;52(3 Pt 1):381-390.

15. Howell MD, Novak N, Bieber T, et al. Interleukin-10 downregulates anti-microbial peptide expression in atopic dermatitis. $J$ Invest Dermatol. 2005;125(4):738-745

16. Hoare C, Li Wan Po A, Williams H. Systematic review of treatments for atopic eczema. Health Technol Assess. 2000;4(37):1-191.

17. Siegfried EC, Jaworski JC, Kaiser JD, et al. Systematic review of published trials: long-term safety of topical corticosteroids and topical calcineurin inhibitors in pediatric patients with atopic dermatitis. $B M C$ Pediatr. 2016;16:75.

18. Giam YC, Hebert AA, Dizon MV, et al. A review on the role of moisturizers for atopic dermatitis. Asia Pac Allergy. 2016;6(2):120-128.

19. Jackson EM. Moisturizers: what's in them? How do they work? Am J Contact Derm. 1992;3:162-168

20. Zuccotti G, Meneghin F, Aceti A, et al. Probiotics for prevention of atopic diseases in infants: systematic review and meta-analysis. Allergy. 2015;70(11):1356-1371.

21. Kober MM, Bowe WP. The effect of probiotics on immune regulation, acne, and photoaging. Int J Womens Dermatol. 2015;1(2):85-89.

22. Boyle RJ. Probiotics for preventing eczema. $\mathrm{Br} J$ Dermatol. 2010;163(3):450.

23. Lew LC, Liong MT. Bioactives from probiotics for dermal health: functions and benefits. J Appl Microbiol. 2013;114(5):1241-1253.

24. Sultana R, McBain AJ, O’Neill CA. Strain-dependent augmentation of tight-junction barrier function in human primary epidermal keratinocytes by Lactobacillus and Bifidobacterium lysates. Appl Environ Microbiol. 2013;79(16):4887-4894
25. Guéniche A, Bastien P, Ovigne JM, et al. Bifidobacterium longum lysate, a new ingredient for reactive skin. Exp Dermatol. 2010;19(8):e1-e8.

26. Marini A, Reinelt K, Krutmann J, et al. Ectoine-containing cream in the treatment of mild to moderate atopic dermatitis: a randomised, comparator-controlled, intra-individual double-blind, multi-center trial. Skin Pharmacol Physiol. 2014;27(2):57-65.

27. Graf R, Anzali S, Buenger J, et al. The multifunctional role of ectoine as a natural cell protectant. Clin Dermatol. 2008;26(4):326-333.

28. Wołosik K, Knaś M, Zalewska A, et al. The importance and perspective of plant-based squalene in cosmetology. J Cosmet Sci. 2013;64(1):59-66.

29. Stettler H, Kurka P, Wagner C, et al. A new topical panthenol-containing emollient: skin-moisturizing effect following single and prolonged usage in healthy adults, and tolerability in healthy infants. $J$ Dermatolog Treat. 2016;28(3):251-257.

30. Thioune O, Khouma B, Diarra M, et al. The excipient properties of shea butter compared with vaseline and lanolin. $J$ Pharm Belg. 2003;58(3):81-84.

31. Luepke NP, Kemper FH. The HET-CAM test: An alternative to the draize eye test. Food Chem Toxicol. 1986;24(6-7):495-496.

32. Marzulli FN, Maibach HI. Contact allergy: predictive testing in man. Contact Dermatitis. 1976;2(1):1-17.

33. Akdis CA, Akdis M, Bieber T, et al. Diagnosis and treatment of atopic dermatitis in children and adults: European Academy of Allergology and Clinical Immunology/American Academy of Allergy, Asthma and Immunology/PRACTALL Consensus Report. J Allergy Clin Immunol. 2006;118(1):152-169.

34. Varothai S, Nitayavardhana S, Kulthanan K. Moisturizers for patients with atopic dermatitis. Asian Pac J Allergy Immunol. 2013;31(2):91-98.

35. Barile FA. Validating and troubleshooting ocular in vitro toxicology tests. J Pharmacol Toxicol Methods. 2010;61(2):136-145.

36. Dekio I, Sakamoto M, Hayashi H, et al. Characterization of skin microbiota in patients with atopic dermatitis and in normal subjects using 16S rRNA gene-based comprehensive analysis. J Med Microbiol. 2007;56(Pt 12):1675-1683

37. Guttman Yassky E, Suárez-Fariñas M, Chiricozzi A, et al. Broad defects in epidermal cornification in atopic dermatitis identified through genomic analysis. J Allergy Clin Immunol. 2009;124(6):1235-1244.

38. Agrawal R, Woodfolk JA. Skin barrier defects in atopic dermatitis. Curr Allergy Asthma Rep. 2014;14(5):433.

39. Bownik A, Stępniewska Z. Ectoine as a promising protective agent in humans and animals. Arh Hig Rada Toksikol. 2016;67(4):260-265.

40. Stettler H, Kurka P, Lunau N, et al. A new topical panthenol-containing emollient: Results from two randomized controlled studies assessing its skin moisturization and barrier restoration potential, and the effect on skin microflora. J Dermatolog Treat. 2017;28(2):173-180.

41. Kim SK, Karadeniz F. Biological importance and applications of squalene and squalane. Adv Food Nutr Res. 2012;65:223-233.

42. Reddy LH, Couvreur P. Squalene: A natural triterpene for use in disease management and therapy. Adv Drug Deliv Rev. 2009;61(15):1412-1426.

43. Essengue Belibi S, Stechschulte D, Olson N. The Use of Shea Butter as an Emollient for Eczema. J Allergy Clin Immunol. 2009;123(2):S41. 